\title{
THE ZOONOSES AND PAEDIATRICS
}

\author{
By R. I. MackaY, M.B., M.R.C.P.(Lond.), D.C.H. \\ Consultant Paediatrician to Hope Hospital, Salford
}

The World Health Organization has adopted and popularized the term 'zoonoses' 1 which is applied to those diseases which are transmissible from animals to man. Altogether a total of some 80 diseases are included among the zoonoses, a word used almost universally in the plural. Most of these diseases have been known for many years and in sorne parts of the world they constitute a major social and economic problem. In depressed populations the morbidity and mortality amongst children is high and chronic infection and infestation are responsible in part for reduced vigour and capacity for work in the young adult. In the United Kingdom many of the well-recognized diseases of earlier times have been controlled almost to the point of extinction, and because of this the subject has received little attention from British writers in recent years. Even less interest has been shown by paediatricians in the zoonoses, perhaps because they are not an important cause of infant mortality or even a common cause of serious illness. Nevertheless there is evidence that certain of the zoonoses occur with sufficient frequency in the British Isles to be included in the differential diagnosis of many febrile conditions which might otherwise remain unexplained.

Although the zoonoses include all diseases transmissible from animals to man, the mode of life in the United Kingdom is such that the source of infection for the majority of persons is likely to be a domestic pet kept in the house though in agricultural communities other domesticated animals may be responsible. Cats, dogs and caged birds have been most frequently incriminated in previous studies but mice, rabbits, fowl and pigeons all feature in their turn. Almost any farm animal may be the source of infection though cattle, sheep, pigs and poultry have been responsible on most occasions.

Hull $^{2}$ tabulates about 20 diseases known to have been carried by dogs and cats, some of them by either animal and approximately half of them infestations. In spite of this knowledge these animals continue to live in close proximity to humans, frequently under unhygienic conditions
- to the disadvantage of both parties. Matheson ${ }^{3}$ estimated in 1944 that the cat population of British cities was approximately ro to I 5 per cent. of the human population and that a city the size of Cardiff would have supported about 30,000 cats. Households in the poorer and older parts of cities are more likely to keep cats than the modern housing estates; 75 per cent. of households in the dock area kept a cat in 1944 as compared with 34 per cent. on : t housing estate. Apart from regulations against pets, the greater incidence of rodent infestation in the poorer quarters was held to account for the difference. In addition to household pets the number of stray cats in British cities is equivalent to about 3 per cent. of the total human population and about 6,000 cats are destroyed per annum by various agencies in each of the large industrial cities. Matheson ${ }^{4}$ also estimated the dog population of Great Britain in r 953 to be equivalent to 6 to 7 per cent. of the adult population and that there were $3,860,000$ dogs in the country in 1950. The numbers of other domestic pets is not estimated but a rapid survey of households in Salford in I955 gave some indication of their popularity. During a routine school medical inspection 128 consecutive children were questioned about pets in the home with the following result:

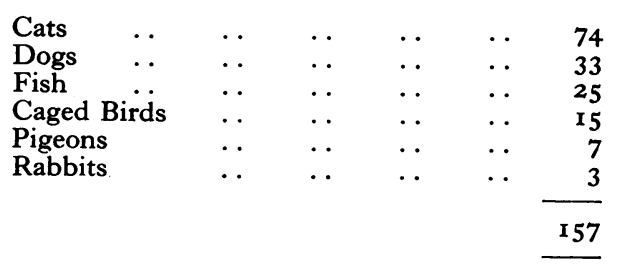

Ninety-one out of 128 households had domestic pets and 36 of these households had two or more pets. The children attended a school in a densely populated industrial area near factories and dockland and lived in terraced houses of the back to back type. A more direct experience, though less well documented, is that of visiting children in their houses as a physician. One often finds the patient 
febrile and with a respiratory infection nursed in a living room with a budgerigar for company or with dog, cat or pet mouse within reach.

The total range of the zoonoses is too extensive for review in a short article and the works of $\mathrm{Hull}^{2}$ and Rivers ${ }^{5}$ should be consulted for complete accounts. We are concerned here with a selection of the zoonoses, those which have been described in Great Britain and, where possible, those which have involved children. It will be seen that the paediatric zoonoses is a neglected topic in this country but one which merits the practical consideration of every family practitioner.

\section{Bacterial Infections}

Tuberculosis. It must be remembered that nonrespiratory tuberculosis of animal origin is a preventable disease and that although great advances have been made in Great Britain in recent years the disease has not been eradicated. In 1953 , 2,260 cases of non-respiratory tuberculosis were notified as occurring in children under $I_{5}$ years of age, ${ }^{6}$ approximately one-third of the total. Since $193^{8}$ the notifications of this disease have been reduced from 6,853 in this age group, though less effectively in other age groups. This improvement is due to the policies of heat treatment of milk and to the attested herds schemes introduced in 1935 and 1950. By September 1952, 37.5 per cent. of cattle in England and Wales were in attested herds. ${ }^{7}$ At the same time 62.5 per cent. of cattle were not.

Cases of cervical adenitis and bone tuberculosis still occur in children who have been allowed to drink raw milk and parents are generally not aware of the risk. In recent years an outbreak of tuberculosis occurred in a village school due to raw milk being served to the children at school. All Education Authorities now serve only heat-treated milk in the School Milk Scheme. Only rarely does a human case infect milk after pasteurization. With correct handling this should not occur. It may not be generally known that Swiss workers have recently shown that the goat is not immune to tuberculosis and can produce infected milk.

Salmonellosis. In view of the greatly increased prevalence of salmonella infections in the last 15 years it is relevant to consider the role of animal vectors. Many of the strains of these organisms recently recognized have been introduced from abroad in food and by human carriers. At the same time salmonellosis is enzootic in the animal population in this country, particularly among rodents. Food stores invaded and contaminated by rats and mice have been the source of explosive outbreaks in institutions and in the population in general. Salmonellosis is enzootic among cats and dogs also, the infection probably acquired from rodents and contaminated food, but possibly in some instances from humans. A survey of 500 dogs and 500 cats carried out in I949 showed an incidence of $I$ per cent. in the former and $I .4$ per cent. in the latter of excretion of pathogens. ${ }^{8}$ In the United States a similar survey showed an incidence among dogs to be as high as 27.6 per cent. Salmonellosis also affects the bird population and in the survey quoted above 2.25 per cent. of a sample of pigeons excreted salmonellae.

It is clear that domestic pets must be included in the general epidemiological study of an outbreak of salmonellosis or in the single case within an apparently healthy family. Moreover the pets must be regarded as equally susceptible in an outbreak and require the same barrier technique when handled or fed.

Dogs and cats excrete helminths and giardia lamblia in even higher proportions but this problem will not be discussed further in this article.

Leptospirosis. This infection is usually considered in differential diagnosis when there is a known occupational risk. Among children the diagnosis is more likely to be missed unless a fulminating infection forces the clinician to recognize the textbook disease. Broom writing in $195^{9}$ analyses the results of investigations for leptospirosis among cases of aseptic meningitis. Among 642 cases of aseptic meningitis, L. icterohaemorrhagiae was involved in 17 and L. canicola in eight. In frank leptospirosis $3^{6}$ children were affected with Weil's disease in a group of 361 patients whose sera were sent to the leptospira reference laboratory, and among 64 cases of canicola fever 15 were children under 15 years of age though only one child was under five years of age. It would appear that these infections are milder in children than in adults and Broom expressed surprise that the infection was only rarely recognized in children. According to the figures he quotes, no child had died of leptospirosis. Weil's disease is mainly an occupational hazard, but children are infected when their curiosity or natural environment brings them in contact with infected rodents, rodent excreta or contaminated water. A case is reported in a child who bathed in stagnant water. In contrast, canicola fever is mainly a domestic hazard and in most cases follows contact with a sick dog. 'The yellows' is not uncommon among dogs and Broom $^{10}$ in another paper estimated that up to 40 per cent. of dogs in Glasgow in 1946 had been infected with L. canicola, and in a survey of 403 dogs of different breeds from several areas in Great Britain he found 27 per cent. with evidence of leptospiral infection. The incidence was lower in agricultural areas than in towns. Broom gives a warning about the care needed in the nursing of 
sick dogs in the home, pointing out that young puppies can be affected and that excretion of leptospira in the urine can continue for many months after the dog's illness.

Classical Weil's disease with septicaemic manifestations, jaundice and nephritis is not likely to pass unrecognized in children, but canicola fever is probably more frequent than we realize. In the form of aseptic meningitis it may be recognized in hospitals sufficiently alert to pursue the diagnosis in a benign and self-limited illness. Moreover leptospırosis may occur as an illness resembling ' influenza' with headache, meningism, conjunctivitis and muscle pains. It may not be sufficiently definite to rouse suspicions of poliomyelitis or similar infections and may never be accurately diagnosed. Jaundice and skin manifestations occur in less than 20 per cent. of patients with canicola fever though albuminuria can be found in 43 per cent. (Broom). During epidemic seasons ' infective hepatitis, is accepted as a diagnosis for children with jaundice and fever. Usually a satisfactory contact history can be obtained. When no contact history is found the matter is rarely pursued unless the course of the illness gives rise to anxiety.

Apart from serological and bacteriological tests which are the only accurate methods of diagnosis, Broom $^{10}$ states that the erythrocyte sedimentation rate is raised in the early stages of leptospirosis as distinct from other forms of ' aseptic' meningitis and that a normal E.S.R. in such a case excludes leptospirosis.

Brucellosis. This infection is not common in this country but the diagnosis is not infrequently made on slender evidence. Official figures report 96 cases of brucellosis in England and Wales in $1953^{11}$ and show an incidence in the rural districts more than ten times that of the county boroughs. It is usually said that children are resistant to infection, but this is denied by Professor Renoux ${ }^{12}$ who asserts that children will become infected if opportunity occurs-' there is no bovine focus of B. melitensis without human cases.' There is even one instance reported of a baby of five months infected by excretion of organisms into his mother's milk. Human brucellosis (abortus) is usually contracted from infected milk, eating unpasteurized cottage cheese and by agricultural contamination. Infections by inoculation of the skin or mucosae or inhalation are more significant in $\mathrm{B}$. melitensis infection.

There is nothing unusual about the clinical picture in childhood; an acute febrile illness occurs or a more prolonged ' pyrexia of unknown origin' characterized by exacerbations and remissions develops. Diagnosis is confirmed by blood culture or agglutination reactions and treat- ment with oxy- or chlor-tetracycline is recommended. Renoux advises the combination of one of these antibiotics with streptomycin. Vaccines are used and on occasion cortisone is used with antibiotics.

Tularaemia. There do not appear to be any case reports of tularaemia in children in the British Isles but it is a recognized hazard of laboratory workers and rabbit fanciers. It is interesting to note a case report from Poland in which Gelber describes eight cases in children of 4 to 14 years who played with the carcase of a hare. All the children involved in the game were ill with sore throat and adenopathy. The diagnosis was confirmed by agglutination reactions and the children successfully treated with chloramphenicol and streptomycin. It may be of interest that the report mentions a yellow coloration of the palms of the hands and the palate, known as Piotrowka's sign, as being helpful in diagnosis. ${ }^{13}$

\section{Viral Infections}

Psittacosis. Ornithosis. Sufficient work has now been done on this disease in man for us to be able to assert that association with psittacine birds, pigeons and fowls increases the risk of the infection. Rivers ${ }^{5}$ states that ' a history of association with birds always suggests a diagnosis of psittacosis in patients with pneumonitis.' In spite of numerous case reports only very few children have been proved to have the disease. Meyer anc Eddie $^{14}$ found no child aged one to nine years in I I I patients with psittacosis in whom the age was recorded on the request to the laboratory, and they mention a German survey in which two children were found to have psittacosis out of a group of I6o patients. Strobel ${ }^{15}$ describes the disease in two children in a family infection and Ellenbogen and Miller ${ }^{16}$ mention a 16 -year-old youth with the disease.

It has been established that the infection in birds is characterized by a viraemia with localization of the virus in spleen, liver and kidneys and that infected birds may excrete virus for a long time, often becoming carriers. The feathers and cage dust are contaminated and inhalation of dust is the usual mode of infection for man. Psittacosis in man is usually a benign illness, but Meyer and Eddie record a mortality of 9.3 per cent. in their series. The disease usually appears as an influenzalike fever with severe headache, sore throat and photophobia with a dry cough. Untreated, the fever may continue into a second week but may fall at the end of seven days. Epistaxis is seen in 25 per cent. but cough may be absent even when there is an extensive pulmonary consolidation. On occasions a typhoid-like illness develops with abdominal symptoms, nausea and diarrhoea. The

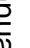
. 
spleen may be enlarged and ' rose spots' appear on the body. It is characteristic that few physical signs can be detected in the chest in the presence of extensive consolidation. Diagnosis is confirmed by inoculation of blood or sputum into mice in the acute stages or by the demonstration of a rising titre of specific complement fixing antibodies during the illness. Although it is generally accepted that the infection responds to penicillin, chlortetracycline is also recommended.

In 95 per cent. of the cases recorded by Meyer and Eddie exposure to birds was recorded, and in 35 per cent. infection was due to pigeons.

Ducks, canaries, chickens and grouse have been proved to be the source of infection. However it is not necessary for a bird to appear ill to be an excretor of psittacosis virus and quarantine regulations only exclude the obviously diseased birds. It is impossible to escape the conclusion that a proportion of acute febrile and respiratory illness in childhood may be due to psittacosis and that the chances are increased in households with caged birds as pets. So far there is no recorded study of the disease among children in this country, though atypical pneumonia of virus origin is not rare. ${ }^{17}$

Canine distemper and feline pneumonia. As long ago as 1928 Bryan showed that canine distemper could be transmitted from man to animals and that children with respiratory infection could transmit an illness to puppies. This work was repeated in I93 I by Nicollé. Adams ${ }^{18}$ in a series of articles from I 94 I to 1953 has attempted to prove that the virus of distemper can produce a respiratory illness in children and adults and that encephalitic symptoms may appear as in puppies. He states that infants and small children may be affected, the severity of the disease decreasing with increasing age. Mortality is high among premature infants. He supports this with evidence drawn from epidemiological studies and from an identity of pathology in animals and man. Human immune serum and human gamma globulin was shown to exert a protective influence in experimental infection comparable with hyperimmune distemper antiserum and ferret immune serum.

There is also a condition known as ' housedog disease 'which is regarded as the common cold transmitted from humans to dogs.

Baker ${ }^{19}$ produced evidence that the virus of feline pneumonia could be transmitted from cats to humans and in one instance from a child to a cat. It is suggested that this virus is antigenically related to the psittacosis-lymphogranuloma group.

Benign inoculation lymphoreticulosis (cat scratch fever). The more imposing title suggested by Mollaret for this disease is perhaps more appropriate than the more popular ' cat scratch fever.' The coup de grace has been administered to this term by the discovery that the disease can be transmitted by other means than by the scratch of a cat.

This adenopathy was recognized by Lee Foshay in 1932 during a study of tularaemia, but little was done to publicize the discovery until Foshay discussed the topic with Debré and a common experience was revealed. Case reports began to appear in French and American literature in $195^{\circ}$. There were over 100 cases in the literature by $195 \mathrm{I}$. Although individual clinicians have recognized cases in children in the British Isles the English literature refers only to adults. ${ }^{23}$ There is no doubt that this disease is quite common among children in this country but is usually unrecognized because it is benign in outcome. With the reduction in the numbers of tuberculous and simple septic glands in recent years, diagnosis should have become easier.

The classical picture is that of suppuration in a lymph node or nodes associated with a variable degree of toxaemia. When the complete history is known a cat scratch or cat bite may be recalled though other modes of inoculation have been recorded. There is usually a mild inflammatory reaction at the site of injury a few days after it occurs. Swelling of regional lymph nodes commences a minimum of four days and a maximum of 28 days after inoculation and may progress through all stages of suppuration to sinus formation with slow healing. Sometimes the swollen glands may form a mass 3 to 4 in. in diameter, but often they are smaller. As would be expected, the adenitis is usually unilateral but bilateral cervical adenopathy has been recorded and there is some evidence that respiratory infection may occur. At the height of the adenitis a variable degree of fever and toxaemia may develop with headache and sometimes a rash. A papule may develop at the site of inoculation at this stage. Greer and Keefer reported an eruption resembling erythema nodosum $^{21}$ in this disease. The differential diagnosis includes septic and tuberculous adenitis, tularaemia, lymphogranuloma and reticuloses including malignant tumours and leukaemia. There is no leucocytosis, pus and glands are sterile on culture and serological investigation is usually negative with occasional positive reaction with antigen prepared for complement fixation tests for lymphogranuloma. The only specific diagnostic test is a skin test resembling a Mantoux reaction performed with antigen prepared from proved cases of the disease. (It is interesting that Daniels and MacMurray ${ }^{20}$ obtained positive skin tests with antigen prepared from cases on both sides of the Atlantic.)

Treatment of the adenopathy is entirely empirical with surgical intervention when indicated. If a sinus forms it may take many weeks to heal, 
but the scar is inconspicuous. Antibiotics have no effect on the inflammation, though tetracyclines have been regarded as helpful.

Although there is an undoubted association with cats, there is no evidence of any disease in the animals responsible for inoculation. It would appear to be an infection passively transferred, almost certainly a virus infection according to Mollaret's study, but a virus as yet unidentified though possibly related to the psittacosis-lymphogranuloma group.

Daeschner et al. ${ }^{22}$ describe 12 cases among children aged from 16 months to ro years collected over a period of 18 months. They describe alternative clinical pictures which are convincing in their context. Apart from local and respiratory infection mentioned above, cough and transient pulmonary infiltration, conjunctivitis with cervical adenitis and a transient severe encephalitis (reported by Stevens) are included. We return with this to the relationship between feline pneumonia and psittacosis. It is certain that these related phenomena form a disease complex which is gradually being elucidated and which is widespread among cat lovers if not in the rest of the population.

Lymphocytic choriomeningitis. In this context it is worth while to consider lymphocytic choriomeningitis shown by Duncan and co-workers in $195 \mathrm{I}^{24}$ to be due in certain circumstances to infection acquired from mice infesting houses or a neighbourhood in which cases occur. In an outbreak in Manchester, Duncan ${ }^{25}$ examined the epidemiology of 24 cases of whom two were children under ro years and two aged ro to r9 years. In addition a boy of seven years was known to have had meningism and fever before his mother developed the typical disease. In this particular district, in contrast to other districts of Manchester investigated, infection of the mouse population with the virus of L.C.M. was demonstrated. Smith and Kinsella ${ }^{26}$ in the same year investigated an epidemic in Co. Durham but made no observations on the number of children involved or on the source, though evidence of infection was found in two Alsatian dogs in a farming community.

Apart from the typical acute meningitis syndrome, Duncan reports proved cases in whom the illness resembled influenza with headache, vomiting, cough, low-grade fever and with photophobia in one-third of these cases. It is of very practical importance that he found the sugar content of the cerebrospinal fluid to be reduced in a number of cases, contrary to orthodox opinion, giving rise to a mistaken early diagnosis of tuberculous meningitis.

It is of great interest to the paediatrician to note that Komrower ${ }^{27}$ has recently described lymphocytic choriomeningitis in a newborn infant in whom transplacental infection is believed to have occurred. The mother lived in the neighbourhood investigated by Duncan after the earlier epidemic.

Epizootic stomatitis (foot and mouth disease). This condition is briefly described in River's textbook as a vesicular stomatitis with fever and salivation. There is a vesicular eruption on the palms of the hands and soles of the feet which spreads to the interdigital clefts. These lesions ulcerate before recovery. This disease may be familiar to country practitioners but it was interesting to encounter a report from Poland (Czarnowski et al. $)^{28}$ of three children living on a farm who developed the disease from infected cattle, the diagnosis being checked by complement fixation tests. Ulceration is described in these children as occurring round the edge of the finger nails. No treatment is recommended.

\section{Rickiettsial Infections}

$Q$ fever. The only rickiettsial infection of any practical importance in Great Britain is $Q$ fever, caused by rickiettsia burneti (also known as Coxiella burneti). Until Stoker reported three cases in 1949 the disease was thought to be a feature of tropical or subtropical countries. Epidemics of ' atypical pneumonia' in troops in the Mediterranean area during the second World War were shown to be due to $\mathrm{Q}$ fever. The increasing interest in the disease is shown by the experience of the Virus Reference Laboratory ${ }^{29}$ of the Public Health Laboratory Service. Out of 700 specimens referred from cases of acute respiratory disease, 3 per cent. showed a significant titre of antibody for R. burneti. In 'atypical pneumonia' 5 per cent. of patients showed significant titres of antibody. Stoker ${ }^{30}$ estimated that 16 per cent. of all pneumonia and unexplained fever in Kent was due to $Q$ fever and that the incidence in the towns might be as high as 25 per cent. Although children have been involved in small outbreaks of $Q$ fever $\left(\right.$ Stoker $\left.^{30}\right)$ and have been studied in epidemiological surveys, it appears that no proved cases of $Q$ fever in children have been recorded in Great Britain to date. Suspicious febrile illnesses and unrelated increase of antibody titre have been observed in children.

There is now a great deal of literature on the epidemiology of $Q$ fever (Babudieri ${ }^{31}$, MacCal$\operatorname{lum}^{32}$, Marmion et al. ${ }^{33}$ ) and it appears that the mode of spread may vary from country to country. At first shown to be carried by ticks in early outbreaks, milk contamination was held responsible in California; in Italy and, more recently, in Great Britain cattle and sheep have been shown to be excretors. The rickiettsiae are excreted in the placenta and uterine discharges of the parturient 
animal and may be found in cow's milk. It is suggested that infected placentae may be eaten by farm dogs and that the dogs become excretors. It has been shown that intestinal passage of the organism is possible in the dog without illness being noticed in the animal. In fact no detectable illness occurs in other animals known to be excretors or to have significant antibody titres. The great resistance of the rickiettsia to drying and the small size make it possible for dust-borne infection to be responsible for epidemic infection. Babudieri describes an epidemic of this type in a village near Ancona. Curiously enough milkborne organisms do not seem to cause illness to the same extent as dust-borne infection, the Californian experience being somewhat unique in the epidemiology. Evidence of infection by fomites has been collected by Marmion ${ }^{37}$ and other workers and has explained epidemics in which there was no obvious occupational risk. Humans very rarely pass the infection to others but this has been recorded in closed hospital communities.

A sufficient number of cases have been described in England to be certain that the disease is not rare (MacCallum, Marmion ${ }^{33}$, Stoker ${ }^{34}$ and others in various papers) and the present localization in Kent is certainly related to the diligence of the investigators. Slavin ${ }^{35}$ has shown a much more widespread infection of cattle. Significant antibody titre was demonstrated in 2.1 per cent. of cattle and in a nation-wide survey he found 6.9 per cent. of infected farms in England, 2.0 per cent. in Wales and 0.8 per cent. in Scotland. Heattreatment of milk destroys rickiettsiae though the organism can survive several weeks in raw milk products.

Infection of the human placenta has been demonstrated and rickiettsiae isolated six months after a clinical infection with $Q$ fever treated with chloramphenicol and tetracyclines. The fate of the baby in this case is not clear. Rickiettsiae can be excreted in human milk but the infant seems to have an acquired immunity. There is of course a risk of infection in banked human milk if inefficiently pasteurized.

In adults the disease takes the form of a sudden fever climbing to a swinging pyrexia over several days and falling by lysis. The incubation period. seems to be 16 to 18 days and there is great prostration with nocturnal delirium, muscle pains, backache and headache. The headache is aggravated by coughing, but there is usually no meningism.

There is an irritating cough but characteristically no evidence of upper respiratory infection. Small areas of crepitations or bronchial breathing may be found in the chest, and inspection of a chest radiograph may reveal rounded peripheral opacities in the lung fields or segmental collapse (Harman ${ }^{36}$ ). Joint pains and swellings, orchitis and encephalitis have been reported, gastrointestinal symptoms are rare, the spleen and lymph glands are usually not enlarged.

The disease carries a very low mortality rate and treatment with chloramphenicol or tetracyclines has been shown to be effective.

Diagnosis is confirmed by isolation of rickiettsiae from blood or sputum in the acute stages, and by complement fixation and agglutination titres compared between the acute and convalescent stages. An intradermal test can be used in confirmation but is fallacious as an isolated diagnostic technique.

Agricultural communities are clearly at risk and after them families who live near cattle markets, abattoirs and railway sidings and those whose houses are situated along streets along which herds are driven from docks or railway stations to the abattoirs. It is probable that infection is to be expected only after long dry periods in summer, at least as far as town populations are concerned.

It would seem that there is every opportunity for widespread infection with R. burneti in these islands and no reason why children should escape. Perhaps the disease is milder in children but after consideration of the history of the recognition of $Q$ fever it is clear that only an enthusiastic investigator in touch with a virus laboratory is required to demonstrate cases among children.

\section{Protozoal Infections}

Toxoplasmosis. Although the existence of the organism Toxoplasma gondii has been recognized for almost half a century, and although human infection was described over 30 years ago, only in the last 1o years has the extent of human infection been appreciated. There is no doubt that countries in which a high incidence has been recorded are those in which enthusiastic investigators have been working. ${ }^{38}$ Nevertheless there is now sufficient evidence to assert that infection with this parasite is quite common in the British Isles and that clinical syndromes have been recognized in infants and young children.

Fisher ${ }^{39}$ reported a series of 100 inpatients at the Hospital for Sick Children, Great Ormond Street, who were tested with toxoplasma antigen as a skin test. Three children showing a positive skin test also showed positive serological reactions and one child among the negative reactors had positive serological reactions. A more extensive survey of 639 mental defective children showed 35 with positive reactions. A review of these studies showed a rising incidence of positive tests in these selected groups from less than I per cent. under four years of age to 17.5 per cent. in children over 
I5 years old. This series is in agreement with reports from other countries in the rising incidence of infection through the years. Macdonald ${ }^{40}$ on the other hand found positive serological tests in only 13 out of 350 healthy adults but positive results were obtained in 10 out of 12 children with chorioretinitis and cerebral calcification. Positive results were obtained in four children among 88 with other congenital anomalies (ages not recorded).

Toxoplasma infection has been demonstrated in many animals and birds. In some countries (Switzerland, Sweden) reservoirs of infection in the animal population have been defined. Although there is little doubt that the organism is the same as that found in human cases, it has not yet been proved that infection is definitely transmitted from animals to man nor the route by which such infection is passed. In the United States two groups of investigators have inferred that domestic dogs have infected the families with whom they lived. Cole et al. ${ }^{41}$ studied 12 volunteer families (involving 37 persons) who owned a total of 28 dogs admitted to the Ohio State University Veterinary Clinic with evidence of toxoplasmosis. No disease was recognized in 35 of these persons and clinical examination was negative. Toxoplasmin skin tests were done and ro persons showed a positive reaction, nine of whom also had significant serological reactions. Doubtful results were found in a further seven persons. Three children under 14 years of age were included. One of these had congenital toxoplasmosis with strongly positive serological reactions and the child's mother also had serological evidence of infection. One three-year-old child had a weakly positive test with a negative skin test and one r2-year-old child had a positive skin test with negative serology. Both were symptom free. Prior et al..$^{42}$ produced further evidence of human infection in association with animal infection. Asymptomatic parasitaemia was discovered in a young woman who kept dogs known to be suffering from toxoplasmosis. A second woman developed toxoplasma encephalitis, her dog being infected previously. A third case described in this series was a 3-yearold child who died of toxoplasmosis with pertussis but no association with pets is recorded.

Infection in man has been recognized as three distinct syndromes at different ages with the added possibility of asymptomatic infection, which has its greatest significance in women of child-bearing age.

Congenital toxoplasmosis is the most frequently described syndrome but it is also the easiest to recognize and may attract more attention because of the extensive damage to the foetus. The affected infant may be born with a hydrocephalus or may develop microcephaly or hydrocephalus shortly after birth. There is usually microphthalmia with enophthalmia. Convulsions may occur and as the months go by mental retardation becomes more obvious. If one adds to this the finding of chorioretinitis and the demonstration of intracerebral calcification on a skull radiograph, the classical clinical syndrome is revealed.

Acquired disease in infancy is known to produce a fatal meningoencephalitis, the diagnosis being made primarily by the pathologist. In adults and older children a rickiettsial type of infection has been described which has many of the features of infectious mononucleosis. Persistent fever of variable degree, adenopathy, splenomegaly and a maculopapular rash have been shown to be due to toxoplasmosis. The rash develops on the trunk and limbs but spares the scalp, palms and soles $\left(\mathrm{Sabin}^{38}\right)$ and may resemble typhus or Rocky Mountain spotted fever. Pneumonitis often occurs, sometimes after the rash has appeared. The syndrome mav resemble glandular fever very closely, and Cathie ${ }^{43}$ found in sera from 20 children and young adults evidence of toxoplasma infection in seven, the patients all having clinical glandular fever with a negative Paul Bunnell reaction.

Skipper et al. ${ }^{44}$ described two cases of this type, one of them a boy of 15 , the diagnosis being made on the basis of serological tests. At the same time they point out that toxoplasmosis is a rare cause of glandular enlargement since the two cases were the onlv examoles among 86 patients.

Diagnosis is established by a positive skin reaction to toxoplasma antigen and by serological tests. The dye test becomes positive early in the disease and the complement fixation test later, though titres fall rapidly. Complete proof is obtained only by isolation of the protozoon by animal inoculation.

Many antiprotozoal agents have been used in attempted treatment of toxoplasmosis with little success. Sulphadimidine, sulphones and pyrimethamine have been used on animals but no clear guidance is available for the treatment of human cases recognized in the acute stage. There is little point in treating chronic infections unless infection is discovered in a pregnant woman.

\section{Parasitic Diseases}

Hull ${ }^{2}$ lists $\mathrm{I} 8$ parasitic infestations transmitted by dogs and 13 transmitted by cats, many of the diseases attributable to either. In this review it is intended to mention only hydatid disease because it has aroused paediatric interest in this country in recent years. Practitioners in South Wales will be more familiar with the disease than others since it is five times as common in Wales than in England and 35 times as common as in Scotland. In a recent communication Gray ${ }^{45}$ reviewed 25 cases of 


\begin{tabular}{|c|c|c|c|}
\hline Disease & Skin Test & Identification of Organism & \\
\hline $\begin{array}{l}\text { Tuberculosis } \\
\text { Brucellosis } \\
\text { Salmonellosis } \\
\text { Leptospirosis } \\
\text { Tularaemia } \\
\text { Psittacosis } \\
\text { Cat Scratch Fever } \\
\\
\text { Distemper } \\
\text { L.C.M. }\end{array}$ & $\begin{array}{c}\text { Mantoux } \\
\text { (doubtful value) } \\
- \\
\text { Foshay } \\
\text { Specific } \\
-\end{array}$ & $\begin{array}{l}\text { Blood culture, urine, faeces. } \\
\text { Blood culture, urine, faeces. } \\
\text { Blood culture, urine, C.S.F. } \\
\text { Blood culture. } \\
\text { Blood, sputum. } \\
\text { C.S.F. } \\
\text { Blood, sputum. } \\
\text { C.S.F. Biopsy. } \\
\text { Biopsy. Sputum. }\end{array}$ & $\begin{array}{l}\text { Agglutination titres. } \\
\text { Agglutination titres. } \\
\text { Agglutination titres. (E.S.R.) } \\
\text { Agglutination titre. } \\
\text { Rising antibody titre. } \\
\text { Low titre lymphogranuloma agglutination } \\
\text { (with negative Frei test). } \\
\text { Complement fixation test. Rising antibody } \\
\text { titre. } \\
\text { Complement fixation test. } \\
\text { Complement fixation. Agglutination titre. } \\
\text { Complement fixation test. Rising dye test } \\
\text { titres. } \\
\text { Complement fixation test. }\end{array}$ \\
\hline
\end{tabular}

The above tests are performed by the laboratories of the Public Health Laboratory Service (except tests for epizootic stomatitis) from whon antigen for skin tests can be obtained.

Specimens for identification of organism should, in general, be sent as early as possible in the disease.

At least two specimens are necessary for precise serological diagnosis, the first early in the disease and the second four to six weeks later.

Special packing is necessary for specimens for virus identification if they must be sent by post.

hydatid disease discovered in children in South Wales. Hepatic cysts were most frequent and pulmonary cysts second in importance. Among 70 cases at a hospital for chest diseases 12 were children with pulmonary cysts. Hepatomegaly in an endemic area strongly suggests a diagnosis of hydatid disease. Cerebral cysts and mesenteric cysts were also encountered but they may occur in any organ.

In what has become a classic review of hydatid disease in the British Isles, Wolfe ${ }^{46}$ in 1943 described a series of 34 cases of whom seven were under 20 years old and the youngest case was a child of two-and-a-half years. Since the silent development of cysts may take many years he suggested that many infections were acquired in childhood or early adult life. Barrett and Thomas ${ }^{47}$ in a review of pulmonary hydatid disease included nine children under ro years of age amcng $7 \mathbf{I}$ cases collected in 14 years. Dogs are implicated as the most important vector in these papers. Barrett and Thomas state that infection is not uncommon in towns if persons keep greyhounds or coursing dogs, but that certain districts or even villages may become important centres of infection.

Diagnosis is confirmed by the Casoni test and by complement fixation tests. The skin test remains positive for years after the removal of the cysts but the complement fixation titre falls rapidly unless active hydatid tissue remains.

The peculiar geographical incidence of hydatid disease is probably due to the unusually high incidence of infestation in sheep from Wales. At the Cardiff abattoir I to 2 per cent. of sheep have hydatid cysts which presumably implies heavy infection of grazing land. Although infection from sheep is possible, human infection usually comes from handling dogs whose coats are contaminated with ova. The dogs are infected from grazing land, from feeding on carcases of dead sheep and from offal from animals slaughtered as diseased. There does not appear to be any reason why South Wales should be more heavily afflicted with hydatid disease than any other area except for the heavier contamination of grazing land which has so far not been eradicated.

\section{Summary}

It is often said that paediatrics and veterinary medicine have much in common. This may be true as far as practice with the younger age groups is concerned but it may be that the connection between the two subjects is more important. Without over-emphasising the frequency of infections transmitted from animals to children it is clear that there is a wide field of investigation for both the laboratory worker and for the family practitioner. It must be remembered that children are the usual source of infection for other children but there are many occasions when this explanation may not be valid. Domestic pets must be included in the consideration of domestic epidemiology.

Consideration of preventive measures involves the proper care of small children and of domestic pets in a common environment. The premature baby and the infant under one year need particular protection. Nor should the protection of animals be 
forgotten. Many thousands of animals and birds are kept in unsatisfactory and unhygienic conditions. The usual practice of accommodating pets in the house leaves much to be desired.

During the preparation of this paper the Paediatric Clinics of North America ${ }^{5 a}$ published a more extensive review of 'Unusual Infections in Childhood' to which practitioners are referred for more detailed accounts of the above diseases and of others common in the United States. There is also a more comprehensive list of references in each section though mainly concerning American literature.

I would like to record my appreciation of the work done by Health Visitors of the City of Salford and their Superintendent, Miss B. Langton, in the short survey of domestic pets described above.

\section{General:}

\section{REFERENCES}

1. 'Advances in the Control of Zoonoses' (1953), WHO/FAO Seminar, Geneva.

2. HULL, T. G. (1955), 'Diseases Transmitted from Animals to Man,' 4th edn., Thomas.

3. MATHESON, C. (1944), F. Anim. Ecol., 13, 130.

4. MATHESON, C. (1953), F. Roy. San. Inst., 73, 143.

5. RIVERS, T. (1954), 'Viral and Rickettsial Infections of Man,' and edn., Lippincot.

5a. 'Pediatric Clinics of North America' (February 1955).

Tuberculosis:

6. 'On the State of the Public Health' (1953), H.M.S.O.

7. WHO/FAO SEMINAR, Annexe 2, p. 25.

Salmonellosis:

8. THOMAS, O. M. (1954), 'The Public Health Aspect of Domestic Animals. 'Dissertation for D.P.H.,' University of Manchester.

Leptospirosis:

9. BROOM, J. C. (1951), Brit. med. F., ii, 689.

I0. BROOM, J. C., and MACINTYRE, A. B. (1948), Vet. Rec., 60,487 .

Brucellosis:

11. 'On the State of the Public Health' (1953), H.M.S.O., p. 97, p. 246.

12. RENOUX, G. E., WHO/FAO Seminar, p. 6r.

Tularaemia:

13. GELBER, J. (1953): Pediatr. Pol., 28/7, 699

Psittacosis, Ornithosis:

14. MEYER, K. F., and EDDIE, B. (1947), F.A.M.A., 133, 822.
15. STROBEL, W. (1954), Deutsch. Med. Wschr., 79/5, 176.

16. ELLENBOGEN, B. K., and MILLER, C. M. (1952), Brit. med.. ., ii, 189 .

17. 'Virus Pneumonia in Children' (1952), Annotation, Lancet i, 803 .

Canine Distemper:

18. ADAMS, J. M. (1953), Pediatrics, II, 15.

Feline Pneumonia:

19. BAKER, J. A. (1942), Science, 96, 475.

Cat Scratch Fever:

20. DANIELS, W. B., and MACMURRAY, F. G. (1951), Arch. int. Med., 33, 736 .

21. GREER, W. E. R., and KEEFER, C. F. (1951), New Eng. F. Med., 244, 545 .

22. DAESCHNER, C. W., SALMON, G. W., and HEYS, F. M. (1953), F. Pediatr., 43, 37I.

23. ANNOTATIONS (1952), Lancet, i, pp. 320, 646, 673, 975.

Lymphotic Choriomeningitis:

24. DUNCAN, P. R., et al. (1951), Lancet, i, 956.

25. DUNCAN, P. R. (1952), 'Thesis for M.D.,' University of Manchester.

26. SMITH, R. C. F., and KINSELLA, J. J. (1951), Lancet, i, 882. 27. KOMROWER, G., et al. (1955), Lancet, i, 697.

Epizootic Stomatitis:

28. CZARNOWSKI, A., et al. (1953), Pediatr. Pol., 28/8, 858.

Q Fever:

29. ANNOTATION (1950), Lancet, ii, 630.

30. STOKER, M. G. P. (1953), Ibid., i, 137.

31. BABUDIERI, B. (1953), WHO/FAO Seminar, p. 157

32. KAPLAN, M. M., and HULSE, E. C. (1953), Ibid., 175.

33. MARMION, B. P., et al. (1594), Lancet, i, 1288.

34. STOKER, B. P. (1954), Trans. Roy. Soc. Trop. Med. Hyg., 48, $19 \mathrm{x}$.

35. SLAVIN, G. (1952), Vet. Rec., 64, 743.

36. HARMAN, J. B. (1952), Postgrad. Med. F., 28, 48 I.

37. MARMION, B. P. (1954), Trans. Roy. Soc. Trop. Med. Hyg. 48, 197 .

Toxoplasmosis:

38. SABIN, A. B. (1942), Advances in Pediatrics, i, $\mathrm{x}$.

39. FISHER, O. D. (195 I), Lancet, i, 904.

40. MACDONALD, A. (1950), Ibid., ii, 560.

41. COLE, G. R., et al. (1953), Arch. int. Med., 92, 308.

42. PRIOR, J. A., et al. (1953), Ibid., 92, 314.

43. CATHIE, I. A. B. (1954), Lancet, i, 813.

44. SKIPPER, E., et al. (1954), Ibid., i, 287.

Hydatid Disease:

45. GRAY, O. P. (1953), Arch. Dis. Child., 28, 243.

46. WOLFE, H. R. I. (1943), Lancet, i, 795.

47. BARRETT, N. R., and THOMAS, D. (1952), Brit. F. Surg., 40, 222.

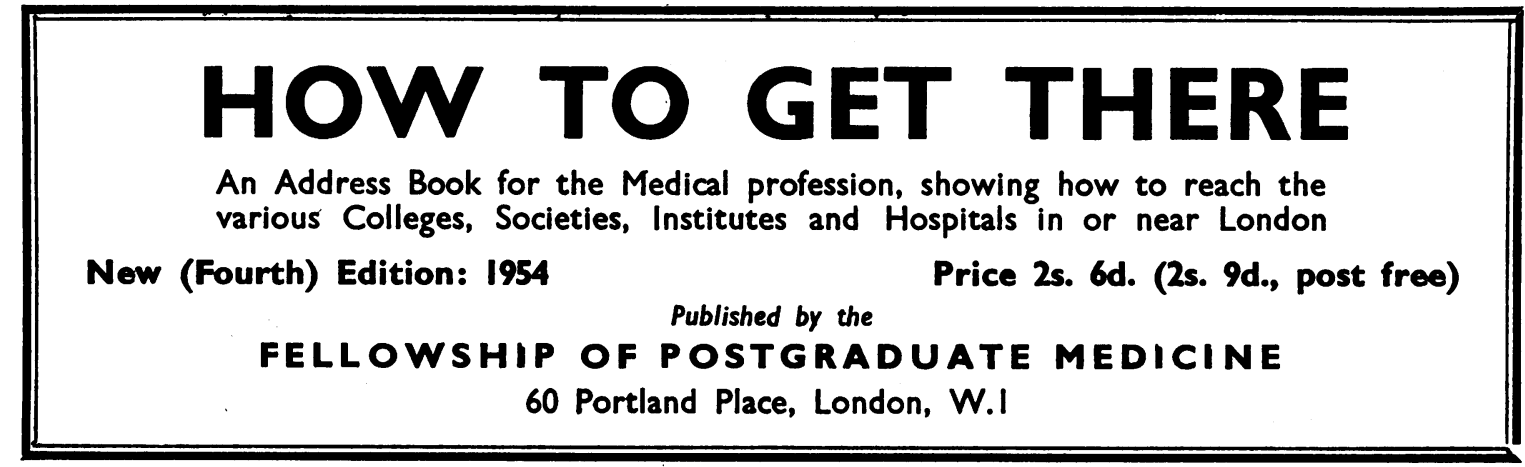

